\title{
Trisomy 21 and the coronavirus disease 2019 (COVID-19)
}

Trisomy 21 is a clinical entity caused by the most frequent chromosomal anomaly among live newborns. ${ }^{1}$ It is characterized by intellectual disability, medical conditions such as hypothyroidism, and a wide range of craniofacial dysmorphisms and congenital malformations. ${ }^{2}$ The life expectancy of subjects with this genetic disorder has increased significantly in recent decades, although this population has a higher risk for neonatal and infant mortality compared to their peers without such chromosomal anomaly ( $1.65 \%$ vs. $0.36 \%$ and $4 \%$ vs. $0.48 \%)$, respectively. ${ }^{1}$ The main causes of mortality include congenital heart disease,,$^{1,2}$ anomalies affecting the nervous system, respiratory system, gastrointestinal tract, urogenital system, and musculoskeletal system, ${ }^{1}$ leukemia, ${ }^{1,2}$ testicular cancer, and sepsis. ${ }^{1}$

Subjects with trisomy 21 may more frequently develop severe, chronic respiratory symptoms because, as mentioned above, there is an association with respiratory anomalies, ${ }^{1,3}$ congenital heart disease, generalized hypotonia, and swallowing problems. ${ }^{1}$ In addition, in many cases such respiratory anomalies may be combined, thus making subjects prone to recurrent respiratory infections, which are the second leading cause of mortality, regardless of age. ${ }^{1,3,4}$

On the other side, subjects with trisomy 21 more frequently have immune system defects, ${ }^{5}$ including deficiencies in innate and adaptive immunity, $\mathrm{B}$ and $\mathrm{T}$ cell abnormalities, ${ }^{1,5}$ primary defect of the B-cell compartment, characterized by a reduced number in peripheral blood, especially memory and immunoglobulin $\mathrm{M}$ cells, which constitute the first line of defense against infections. ${ }^{1}$ At the level of innate immunity, altered gamma delta $\mathrm{T}$ cell function, inflammasome, Toll-like receptors and their pathways may interfere with an adequate response. In addition, monocyte abnormalities, neutrophil chemotaxis, circulating cytokines, and abnormal antibody responses contribute to a higher risk for infections and are, in turn, related to a poor prognosis. ${ }^{5}$ It has also been demonstrated that these subjects have a poor response to primary immunization and their protection may require tailored vaccination protocols. The American Academy of Pediatrics currently recommends the pneumococcal and influenza vaccines and palivizumab use because they are at risk for severe respiratory syncytial virus infections. ${ }^{1}$

The recent outbreak of severe pneumonia associated with the novel coronavirus SARSCoV-2 (COVID-19) has now become a worldwide emergency, putting public health institutions around the globe on high alert. ${ }^{6}$ We now face a global challenge with limited clinical and therapeutic information, which calls for ongoing scientific updates.

Therefore, preventive measures still play a major role in the management and prevention of COVID-19 spreading, especially in the case of subjects with respiratory anomalies and the other risk factors mentioned above. ${ }^{6}$ Although these measures are widely disseminated by the media, social networks, and other sources, paradoxically, easily preventable mistakes still take place. These measures should be followed not only by subjects with trisomy 21 , but also by their families and any person who comes into contact with them, and this is probably one of the most important mistakes. On the other side, an unnecessary exposure should be avoided, thus emphasizing the main recommendation: stay home. The creativity required to make the most of time and have a more bearable lockdown comes from home. We must all fight this battle; only together we will be able to return, as soon as possible, to our now long-awaited normality.

Different foundations for trisomy 21 have proactively participated in the dissemination of information, thus offering a great support to families. Therefore, the message should not be alarming but cautious. The involvement of individuals with trisomy 21 in different campaigns is aimed at developing greater awareness and sensitivity among the general population, who has the duty to protect and safeguard the well-being of subjects with this genetic condition.

Worldwide, more than one billion people have a disability, and the SARS-CoV-2 (COVID-19) pandemic will probably affect them to a higher rate, thus putting them at a higher risk for morbidity and mortality. This underscores the urgent need for improving, making more accessible, and prioritizing the health care services provided to this group of patients. Particularly, in low- and middle-income countries, the health 
system response may be affected by the lack of planning, preparation, and possibility of providing an actually inclusive and accessible response to this vulnerable population. ${ }^{7}$

According to the Revista Virtual Sindrome de Down, ${ }^{8}$ it is known that some subjects with SARSCoV-2 (COVID-19) infection have had a variable course, from recovery to death. Therefore, a new question arises about whether the trisomy 21 population is more commonly affected than the rest of the population and whether they develop a more severe form, so their study is only beginning. ${ }^{8}$

Given the characteristics of trisomy 21, this population should be considered at risk, regardless of age, not only for SARS-CoV-2 (COVID-19), but also for other infectious agents described before. Its management should be specific and customized because it requires an appropriate assessment and follow-up.

As a result, an adequate use of drugs, immunizations, and prophylactic agents is to be implemented, which may be useful to reduce the different complications that may occur in these subjects. Therefore, pediatricians and all health care staff members in general should commit and make an effort to compile the necessary clinical data, including case sampling, in order to broaden the knowledge of clinical characteristics, prevention, infectious agent pathogenesis, and host response. ${ }^{9}$

\section{Dedication}

This article is dedicated to people with trisomy 21, whose well-being and care is the object of our commitment.

We would like to thank the "white task force", the entire health care team that, with knowledge and courage, fights in this complex battle.

Prof. Francisco Cammarata-Scalisi, ${ }^{,}$ Prof. Antonio Cárdenas Tadich, M.D., ${ }^{a}$ Marco Medina, M.D., ${ }^{a}$ and Michele Callea, M.D. ${ }^{b}$

a Department of Pediatrics, Hospital Regional de Antofagasta, Chile.

b Unit of Dentistry, Bambino Gesù Children's Hospital, IRCCS, Rome, Italy. francocammarata19@gmail.com dr_cardenas2000@yahoo.es http:/ / dx.doi.org/10.5546/ aap.2020.eng.230

To cite: Cammarata-Scalisi F, Cárdenas Tadich A, Medina M, Callea M. Trisomy 21 and the coronavirus disease 2019 (COVID-19). Arch Argent Pediatr 2020;118(4):230-231.

\section{REFERENCES}

1. Valentini D, Di Camillo C, Mirante N, Marcelini V, et al. Effects of Pidotimod on recurrent respiratory infections in children with Down syndrome: a retrospective Italian study. Ital J Pediatr. 2020;46(1):31.

2. Fisher PG. Who should care for children with Down syndrome? J Pediatr. 2020;218:1-4.

3. De Lausnay M, Verhulst S, Boel L, Wojciechowski M, et al. The prevalence of lower airway anomalies in children with Down syndrome compared to controls. Pediatr Pulmonol. 2020 [Epub ahead of print].

4. Kusumoto Y, Imai K, Ohyama Y, Fukayama H, Shinozuka O. Oral management of a patient with Down syndrome and agammaglobulinemia: a case report. BMC Oral Health. 2020;20(1):71.

5. HuggardD, Doherty DG, Molloy EJ. Immune dysregulation in children with Down syndrome. Front Pediatr. 2020;8:73.

6. Marraro GA, Spada C. Consideration of the respiratory support strategy of severe acute respiratory failure caused by SARS-CoV-2 infection in children. Zhongguo Dang Dai Er Ke Za Zhi. 2020;22(3):183-94.

7. Armitage R, Nellums LB. The COVID-19 response must be disability inclusive. Lancet Public Health. 2020 [Epub ahead of print].

8. COVID-19 Nadie lo había invitado. Revista Virtual Síndrome de Down. 2020; 227. [Accessed on: April $3^{\text {rd }}, 2020$ ]. Available at: https: / / www.down21.org/revista-virtual/1774revista-virtual-sindrome-de-down-2020 / revista-virtualabril-2020-n-227 /3436-covid-19-nadie-lo-habia-invitado. html

9. Britton PN, Marais BJ. Questions raised by COVID-19 case descriptions. J Paediatr Child Health. 2020 [Epub ahead of print]. 